\title{
Behavior of Enterobacter pulveris in amorphous and crystalline powder matrices treated with supercritical carbon dioxide
}

\author{
M. Callanan, ${ }^{\star 1}$ M. Paes, ${ }^{\star}$ C. Iversen, ${ }^{\star}$ R. Kleijn, $\dagger$ C. Bravo Almeida, ${ }^{\star}$ W. Peñaloza, ${ }^{\star}$ N. Johnson, ${ }^{\star}$ G. Vuataz, ${ }^{\star}$ \\ and M. Michel* \\ *Nestlé Research Centre, Nestec Ltd., Vers-Chez-Les-Blanc, 1000 Lausanne 26, Switzerland \\ †Nestlé Product Technology Centre, $\mathrm{CH}-3510$ Konolfingen, Switzerland
}

\begin{abstract}
The resistance of an Enterobacter pulveris strain to combined heat and supercritical carbon dioxide $\left(\mathrm{scCO}_{2}\right)$ treatments in different powder matrices was examined. The strain proved resistant to $\mathrm{scCO}_{2}$ treatment up to $50 \mathrm{MPa}$ pressure at temperatures $>73^{\circ} \mathrm{C}$ for at least 20 min in a commercial infant formula. Water availability was shown to be important for the observed thermotolerance, because introduction of water in the $\mathrm{scCO}_{2}$ gas flow during treatment resulted in a $1 \log _{10} \mathrm{cfu} / \mathrm{g}$ reduction of the initial inoculum. Interestingly, similar tolerance to heat and $\mathrm{scCO}_{2}$ treatment was observed in a less complex matrix, a maltodextrin powder. In contrast, the bacterial strain proved sensitive to lower temperatures $\left(55-65^{\circ} \mathrm{C}\right)$ over shorter times $(\leq 10 \mathrm{~min})$ in a dextrose powder composed of crystalline particles. Therefore, the microorganism demonstrates heat sensitivity in the crystalline powder matrix closer to that of nonpowder liquid matrices. These data demonstrate the increased heat tolerance of the bacterium specifically in amorphous powders and indicate that this characteristic is not dependent on fat and other components commonly found in infant formula. The information is important in designing strategies to deal with contamination of powders with Enterobacteriacae, including pathogenic Cronobacter spp.
\end{abstract}

Key words: food powder, supercritical carbon dioxide, Enterobacter, water activity

\section{INTRODUCTION}

Cronobacter spp. (formerly Enterobacter sakazakii) are opportunistic pathogens linked to life-threatening infections in neonates, and contaminated powdered infant formula has been epidemiologically linked to

Received March 16, 2012.

Accepted July 8, 2012.

${ }^{1}$ Corresponding author: michaeljohn.callanan@rdls.nestle.com infections (Healy et al., 2010). The primary interventions in powdered infant formula (PIF) are thermal inactivation of microorganisms during processing and the low water activity $\left(\mathbf{a}_{\mathrm{w}}\right)$ of the powder matrix. Cronobacter spp. and other Enterobacter species have a high tolerance for desiccated environments and have been isolated from PIF and other dry infant products despite thermal treatment during production (Chap et al., 2009; O'Brien et al., 2009; Kandhai et al., 2010). Such problems have been linked to contamination in processing sites (Reich et al., 2010) and in the ingredients used to produce these sensitive infant products (Mullane et al., 2008; Lehner et al., 2010; Jacobs et al., 2011; Walsh et al., 2011). Therefore, it is essential to develop new interventions applicable to products or ingredients in powdered form to minimize the probability of posttreatment contamination and to ensure safety of the formula. However, powder microflora has a naturally high thermal resistance and decontamination of powders is difficult (Fine and Gervais, 2005; Laroche et al., 2005). Water activity and granulometry have been shown to influence the heat tolerance of dried microorganisms (Fine et al., 2005) and this resistance is best understood for Salmonella (Podolak et al., 2010). The available data for Enterobacter focus on heat resistance in reconstituted infant formula (Walsh et al., 2011) and the effects of elevated storage temperatures on the long-term persistence of these bacteria in PIF (Beuchat et al., 2009). A recent study has indicated that 2 heatresistant Cronobacter phenotypes may exist in liquid media (Gajdosova et al., 2011) but no studies, to our knowledge, document the resistance of Enterobacter species to heat treatment in a powder matrix.

For almost 2 decades, the use of high-pressure $\mathrm{CO}_{2}$ has been proposed as an alternative nonthermal pasteurization technique for foods (Garcia-Gonzalez et al., 2007). In this technique, food is contacted with (pressurized) sub- or supercritical $\mathrm{CO}_{2}$ for a certain amount of time in a batch, semi-batch, or continuous manner. Supercritical $\mathrm{CO}_{2}\left(\mathbf{s} \mathbf{c} \mathbf{C O}_{2}\right)$ is $\mathrm{CO}_{2}$ at a temperature and pressure above its critical-point values and it exists 
as a single phase. It has the unique ability to diffuse through solids like a gas and to solubilize materials like a liquid. Most of the scientific reports describe the use of $\mathrm{scCO}_{2}$ for pasteurization of liquid foods, although some papers report the treatment of other food matrices with $\mathrm{scCO}_{2}$, but these are limited (Garcia-Gonzalez et al., 2007).

A recent study demonstrated that $\mathrm{scCO}_{2}$ could be applied to reduce Cronobacter in powdered infant formula (Kim et al., 2010). However, from an industrial perspective, the treatment conditions involved relatively high temperatures for long periods. The initial objective of this study was to investigate if a similar reduction in bacterial numbers could be achieved in a shorter time at higher pressure. In addition, we explored the effect of different powder matrices on bacterial resistance.

\section{MATERIALS AND METHODS}

\section{Test Organisms and Materials}

Enterobacter pulveris strain 1160/04 is a fruit powder isolate that shares several typical characteristics with Enterobacter sakazakii, including resistance to desiccation (Stephan et al., 2008). A commercially available first-stage infant formula was used in the trials. Maltodextrin DE 2/5 (Roquette, Lestrem, France) and anhydrated and monohydrated dextrose (VWR, Darmstadt, Germany) were sourced from commercial suppliers.

\section{Sample Powder Preparation}

The strain was cultured on Enterobacter sakazakii selective agar (AES, Rennes, France), and the powder inoculum was prepared by harvesting an overnight culture grown in a screw-capped conical tube in nonselective tryptic soy broth (TSB, Oxoid, Basingstoke, UK) using centrifugation at $3,000 \times g$ for $10 \mathrm{~min}$. Excess liquid was removed from the pellet using a micropipette and the pellet was allowed to dry for $30 \mathrm{~min}$ in a laminar flow hood. The inoculated powder was prepared by dry mixing the pellet using a glass rod in 1- to 20-g aliquots until $100 \mathrm{~g}$ of powder had been added per pellet derived from $50 \mathrm{~mL}$ of overnight culture. This protocol produced an initial population of between 4 and $5 \log _{10} \mathrm{cfu} / \mathrm{g}$. Homogeneity of the inoculum was determined by assaying (see below) a minimum of 8 independent samples per powder and varied (SD) by 0.2 to $0.3 \log _{10} \mathrm{cfu} / \mathrm{g}$, with the exception of the maltodextrin powder, which varied by $0.48 \log _{10} \mathrm{cfu} / \mathrm{g}$. The samples were stored aerobically in screw-capped, glass bottles at room temperature $\left(15-20^{\circ} \mathrm{C}\right)$ for at least 48 $\mathrm{h}$ before treatment.

\section{Supercritical $\mathrm{CO}_{2}$ Treatment}

A schematic of the $\mathrm{scCO}_{2}$ system used is shown in Figure 1. A high-pressure view cell was supplied by NWA (Lorrach, Germany). The cell has a maximum volume of $60 \mathrm{~mL}$ and is designed for maximum operating conditions of $70 \mathrm{MPa}$ and $250^{\circ} \mathrm{C}$. The 3 -g powder samples were weighed in 5 -mL plastic boats, loaded into the view cell, and sealed. Carbon dioxide (99.5\% purity; Carbagas, Gümligen, Switzerland) was injected into the extractor using a $\mathrm{CO}_{2}$ gas pump. The valve was locked when the designated pressure was reached and the $\mathrm{scCO}_{2}$ treatment was performed. After the treatment was completed, the vessel was rapidly depressurized. The $\mathrm{CO}_{2}$ was completely removed from the extractor and the sample retrieved. The retrieved samples were held at room temperature before viable cell counts of pre- and posttreatment samples were determined. Where indicated, the inactivation effects of $\mathrm{scCO}_{2}$ on E. pulveris $1160 / 04$ were compared with equivalent treatments in the equipment without $\mathrm{scCO}_{2}$.

For experiments in which water was introduced into the $\mathrm{CO}_{2}$ stream, an SFE-1000 supercritical fluid extraction system (Thar Technologies, Pittsburgh, PA) was used. A 50-g sample of inoculated PIF was placed in a cylindrical product basket (volume of $500 \mathrm{~mL}$ ), equipped with metallic filters $(100 \mu \mathrm{m})$ at top and bottom. The basket was loaded into the 1-L chamber (see Figure 1B). The temperature and time of treatment were kept constant and a pressure of 20 or $50 \mathrm{MPa}$ was applied. When the treatment conditions were reached, water was introduced at $1 \mathrm{~g} / \mathrm{min}$ into the $\mathrm{scCO}_{2}$ stream (100 $\mathrm{g}$ of $\left.\mathrm{scCO}_{2} / \mathrm{min}\right)$ using the modifier pump. After the water was added, the $\mathrm{scCO}_{2}$ stream was stopped to avoid direct drying of the infant formula. Finally, the infant formula was extracted for $10 \mathrm{~min}$ to remove the added water and minimize any effect on the final product.

\section{Enumeration of Enterobacter}

Bacterial counts were determined using a spot plating method. Samples $(0.1 \mathrm{~g})$ of powders were harvested in sterile $1-\mathrm{mL}$ plastic tubes and serially decimally diluted in $0.9 \mathrm{~mL}$ of buffered peptone water. Twenty microliters of each dilution was spotted in triplicate on tryptic soy agar plates to enumerate the bacteria. Then, $100-\mu \mathrm{L}$ aliquots of each dilution were added to $100 \mu \mathrm{L}$ of TSB, incubated overnight at $30^{\circ} \mathrm{C}$, and spotted using a multiinoculator on Enterobacter sakazakii selective agar in 96-well plates for most-probable-number (MPN) calculations and to confirm that the recovered bacteria were indeed Enterobacter. 

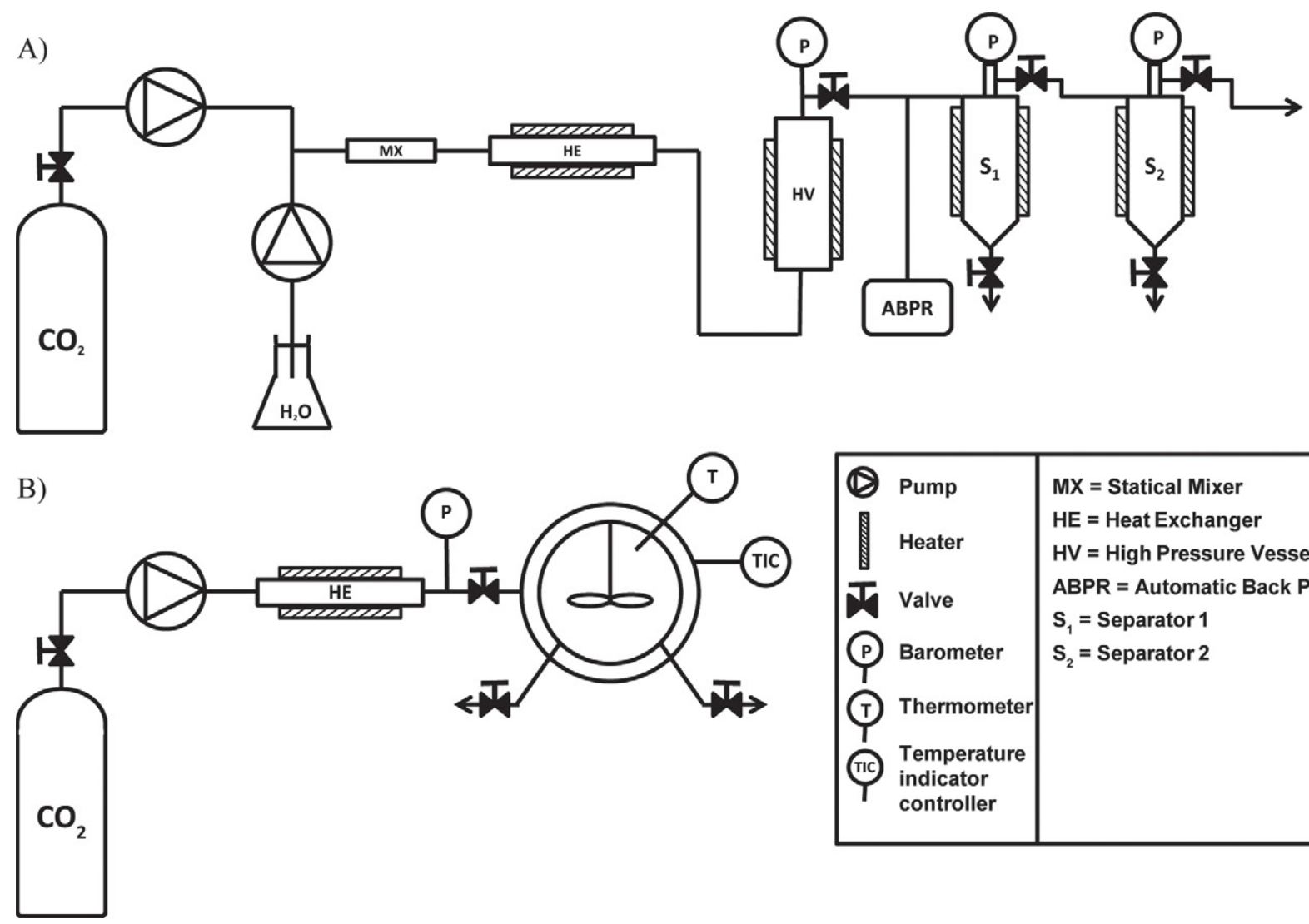

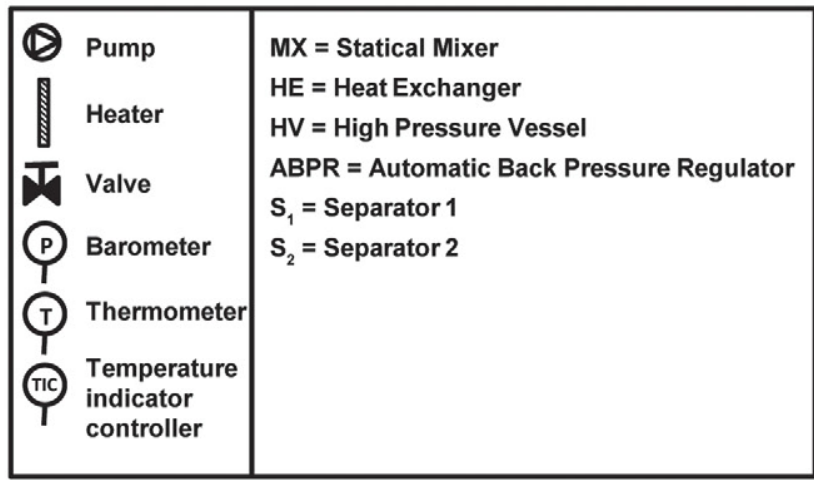

Figure 1. Schematic of the supercritical $\mathrm{CO}_{2}$ equipment: A) chamber, B) view cell.

\section{Determination of Water Activity}

Water activities of all powders before and after treatment were determined using an Aqualab CXT-2 (Decagon Devices Inc., Pullman, WA), which calculates the value from the vapor pressure in the headspace using a cooled-mirror dewpoint sensor.

\section{RESULTS}

\section{Treatment of Enterobacter-Inoculated Infant Formula with $\mathrm{scCO}_{2}$}

Kim et al. (2010) demonstrated that Cronobacter sakazakii could be eliminated $\left(>6 \log _{10} \mathrm{cfu} / \mathrm{g}\right.$ reduction) from infant formula treated with $\mathrm{scCO}_{2}$ using relatively mild conditions of $20 \mathrm{MPa}$ and $73^{\circ} \mathrm{C}$ for 20 min. In this study, we investigated whether the holding time could be reduced to a more industrially relevant (shorter) time by increasing the pressure. In addition, we used an isolate of Enterobacter pulveris (rather than C. sakazakii) because it is nonpathogenic and thus can be used in food production trials. This E. pulveris strain was isolated directly from a commercial powder product rather than the production environment, indicating its potential to persist in a powder. Taking the effective conditions from the previous study as our median treatment, we tested combinations of shorter times with increased pressure (Table 1). In addition, we tested the effect of increased pressure over a shorter time with higher and lower temperatures. In contrast to Kim et al. (2010), we observed no significant reductions in the numbers of inoculated E. pulveris under all conditions.

Several factors could explain the difference between our results and those of Kim et al. (2010). First, the E. pulveris $1160 / 04$ strain may be more resistant to the treatments tested even though it was isolated from the same ecological niche as Cronobacter spp. However, for practical application of the technology, the testing of environmentally hardened strains is essential. Second, different powders and inoculation methods were used in the current study. It is clear that $\mathrm{a}_{\mathrm{w}}$ affects the survival of Enterobacteriaceae in PIF over prolonged periods (Beuchat et al., 2009). The potential effects of the different powders and inoculation protocols on $\mathrm{a}_{\mathrm{w}}$ 
Table 1. Effect of supercritical $\mathrm{CO}_{2}$ treatments on reduction in bacterial count of infant formula inoculated with Enterobacter pulveris

\begin{tabular}{lllccc}
\hline & & & \multicolumn{3}{c}{ Reduction in count, $\log _{10} \mathrm{cfu} / \mathrm{g}$} \\
\cline { 4 - 6 } $\begin{array}{l}\text { Pressure } \\
\mathrm{MPa}\end{array}$ & $\begin{array}{l}\text { Time, } \\
\text { min }\end{array}$ & $\begin{array}{l}\text { Water } \\
\text { added, }{ }^{1} \mathrm{~g}\end{array}$ & $68^{\circ} \mathrm{C}$ & $73^{\circ} \mathrm{C}$ & $80^{\circ} \mathrm{C}$ \\
\hline 50 & 10 & 0 & $0.09 \pm 0.09$ & $0.29 \pm 0.16$ & $0.30 \pm 0.28$ \\
50 & 10 & 3.2 & & $1.19 \pm 0.08$ & \\
50 & 20 & 0 & & $0.04 \pm 0.17$ & \\
20 & 20 & 0 & & $0.00 \pm 0.10$ & \\
20 & 10 & 1.6 & & $1.00 \pm 0.07$ & \\
20 & 10 & 3.2 & & $1.26 \pm 0.12$ & \\
\hline
\end{tabular}

${ }^{1}$ Initial inoculum was $5.81 \pm 0.09 \log _{10} \mathrm{cfu} / \mathrm{g}$ for trials without water and $4.81 \pm 0.12 \log _{10} \mathrm{cfu} / \mathrm{g}$ with water.

were therefore considered particularly relevant. To investigate the importance of water availability to $\mathrm{scCO}_{2}$ efficacy, inoculated powder was treated with either 1.6 or $3.2 \mathrm{~g}$ of water added to the $\mathrm{CO}_{2}$ stream before introduction to the chamber. The 3.2-g amount represents the maximum volume of water soluble in the $\mathrm{scCO}_{2}$ stream under the experimental conditions, according to previous experiments (Wiebe and Gaddy, 1941). This modified procedure resulted in a small but measurable $1 \log _{10} \mathrm{cfu} / \mathrm{g}$ reduction in Enterobacter (Table 1 ). Therefore, the efficacy of the treatment was improved, confirming the importance of water availability in eliminating the bacterium.

\section{Treatment of Enterobacter-Inoculated Maltodextrin with $\mathrm{scCO}_{2}$}

The possibility of increasing efficacy by introducing water in the $\mathrm{scCO}_{2}$ stream would be consistent with an attractive and environmentally clean nonthermal processing technology for infant formula. The previous results raised an interesting question about the role of $\mathrm{a}_{\mathrm{w}}$ in survival of Enterobacter in powder matrices. However, infant formula is a heterogeneous mix of components with varying $\mathrm{a}_{\mathrm{w}}$. Therefore, to better understand the effect of introduced water on the microorganisms in the powder and the efficacy of the treatment, the response of E. pulveris $1160 / 04$ to $\mathrm{scCO}_{2}$ treatment in a simple sugar powder was first determined. Maltodextrin is a component of infant formula, and we chose a maltodextrin DE $2 / 5$ powder because the treatment conditions of high temperature $\left(60-70^{\circ} \mathrm{C}\right)$ and increased $\mathrm{a}_{\mathrm{w}}$ due to the introduced water would not exceed the gelling temperature of a powder with this specification.

The inoculated maltodextrin powder was prepared following the same protocol as the infant formula. The powder was treated at $20 \mathrm{MPa}$ and $73^{\circ} \mathrm{C}$ for 20 min with and without the addition of water to the $\mathrm{scCO}_{2}$ stream. Furthermore, the effect of higher pressure combined with a shorter time was determined. Interestingly, the bacteria proved as resistant to the high-temperature
$\mathrm{scCO}_{2}$ treatments and pressures in the maltodextrin powder as in the infant formula under the same conditions (Figure 2). In nonpowder matrices, Enterobacter spp. are not particularly resistant to heat treatment, with decimal reduction time values ( $D$-values) between 0.3 and 0.5 min at $58^{\circ} \mathrm{C}$ (Breeuwer et al., 2003). Therefore, the behavior in a powder consisting of the sugar component alone afforded sufficient protection for the bacteria against a normally lethal temperature. A protective role for various components has been postulated as being important for survival of microorganisms in powdered foods (Laroche et al., 2005). However, in the absence of the protein and fat components of infant formula, E. pulveris $1160 / 04$ in a simple powder matrix remained tolerant of the high temperatures and the $\mathrm{scCO}_{2}$ treatment used in this study.

\section{Treatment of Enterobacter-Inoculated Anhydrated and Monohydrated Dextrose with $\mathrm{scCO}_{2}$}

To further investigate the effect of $\mathrm{a}_{\mathrm{w}}$ on the survival of E. pulveris 1160/04 in powder matrices and its effect on the application of $\mathrm{scCO}_{2}$ treatment, we investigated the behavior of the bacteria in a crystalline powder matrix. A crystalline matrix will not absorb water under our experimental conditions of temperature and pressure. Therefore, we selected a crystalline matrix to eliminate the possibility that the water introduced in the $\mathrm{scCO}_{2}$ stream in the PIF experiments described above was simply absorbed by the powder component, making it unavailable for inactivation of the microorganisms. We also decided to compare survival after treatment of inoculated anhydrated and monohydrated dextrose powders. At the proposed treatment temperature of $73^{\circ} \mathrm{C}$, monohydrated dextrose releases its water and the effect of increasing $\mathrm{a}_{\mathrm{w}}$ could be measured without having to add water exogenously to the $\mathrm{scCO}_{2}$ stream as in previous experiments.

The effect of E. pulveris inoculation and subsequent $\mathrm{scCO}_{2}$ treatment on the dextrose powders was completely different from that observed for PIF and 


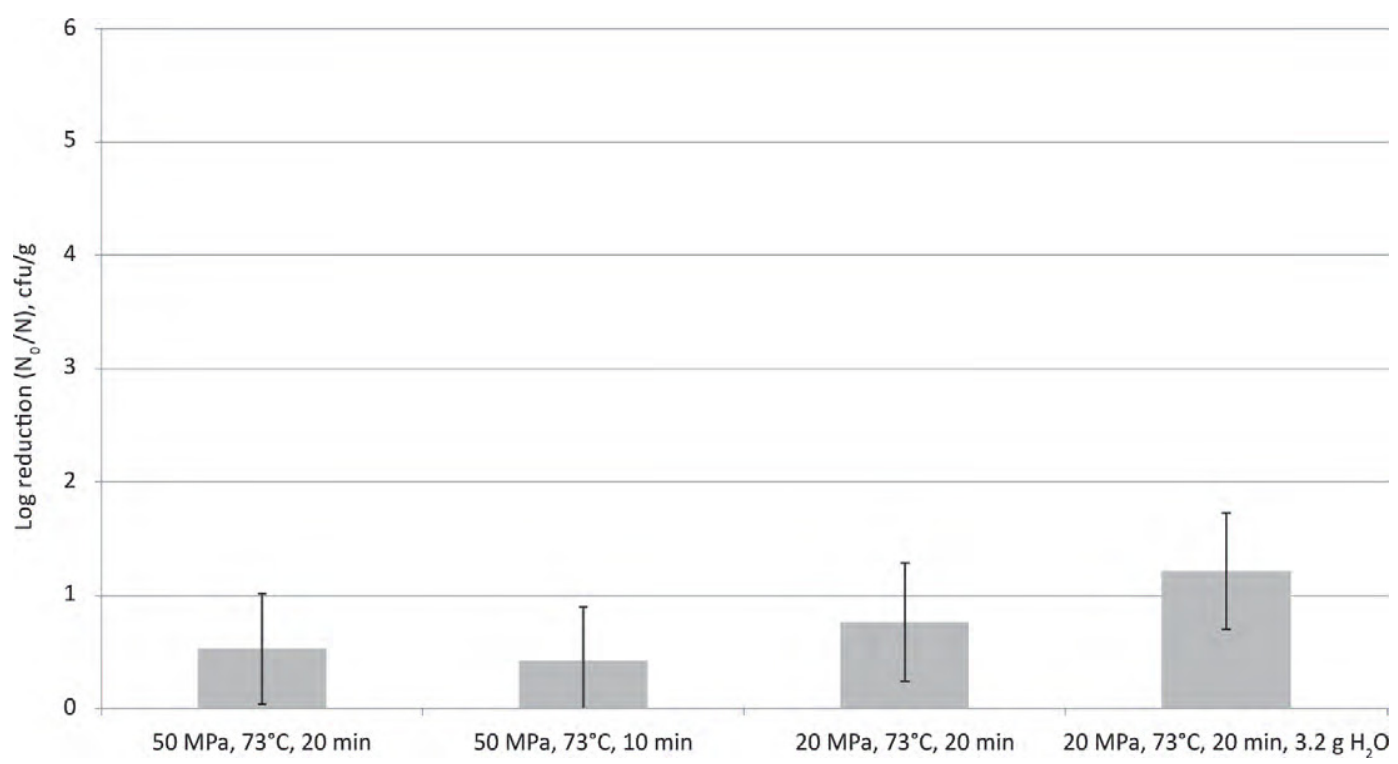

Figure 2. Effect of supercritical $\mathrm{CO}_{2}$ treatment of maltodextrin inoculated with Enterobacter pulveris (initial inoculum of $5.53 \pm 0.47 \log _{10}$ cfu/g). No significant differences were observed between treatments. $\mathrm{N}_{0}=$ initial count $(\mathrm{cfu} / \mathrm{g}) ; \mathrm{N}=$ final count $(\mathrm{cfu} / \mathrm{g})$.

maltodextrin. Following the same treatment conditions (20 or $50 \mathrm{MPa}$ at $73^{\circ} \mathrm{C}$ for 10 or $20 \mathrm{~min}$ ) that had an insignificant effect in the other powder matrices, we failed to recover the inoculated bacteria. In fact, treatment at $20 \mathrm{MPa}$ and $73^{\circ} \mathrm{C}$ for only $10 \mathrm{~min}$ was sufficient to eliminate the 3.5 to $5 \log _{10} \mathrm{cfu} / \mathrm{g}$ bacteria in both powder matrices. To understand this result, we investigated the 2 critical parameters of temperature and $\mathrm{a}_{\mathrm{w}}$. First, the $a_{w}$ measurement of the dextrose powders was found to have changed from 0.2 before inoculation to 0.5 following inoculation. We observed no such change for the other powders (data not shown) but it should be noted that these measurements are only indicators of changes in $\mathrm{a}_{\mathrm{w}}$ and are not definitive values because they rely on dewpoint calculations (which are less accurate for low $\left.a_{w}\right)$ and the powders were not equilibrated beforehand. To eliminate the possibility that the effect was simply temperature related, the same treatments were applied in the anhydrated dextrose at lower temperatures with and without $\mathrm{scCO}_{2}$. The inoculated powder was treated for $10 \mathrm{~min}$ with increasing temperature increments from 50 to $70^{\circ} \mathrm{C}$ at $20 \mathrm{MPa}$ with and without $\mathrm{scCO}_{2}$ (Figure $3)$. The results confirmed that the E. pulveris strain in the crystalline powder demonstrated heat resistance closer to that of Enterobacter in nonpowder matrices. No bacteria were recovered after $10 \mathrm{~min}$ at $65^{\circ} \mathrm{C}$ compared with no effect after $20 \mathrm{~min}$ at $73^{\circ} \mathrm{C}$ in amorphous powders. Interestingly, treatment with $\mathrm{scCO}_{2}$ at $55^{\circ} \mathrm{C}$ proved sufficient, demonstrating that the $\mathrm{scCO}_{2}$ had a measurable effect with the crystalline matrix.

\section{DISCUSSION}

Cronobacter spp. contamination of PIF is of serious concern to the food industry, and understanding the behavior of contaminating microorganisms in powder matrices is critically important. In this study, we examined the resistance of an Enterobacter strain, E. pulveris $1160 / 04$, isolated from a powder product, to combined heat and $\mathrm{scCO}_{2}$ treatments in different powder matrices. The results confirmed the high temperatures required to effect a reduction in Cronobacter spp. inoculated in powder compared with liquid matrices observed by Kim et al. (2010). In addition, the thermotolerance of a simple maltodextrin powder was found comparable to that of more complex infant formulas, which indicates that the ineffectiveness of heat in the powder matrix was not dependent on the fat and other components of infant formula. Furthermore, the importance of the powder composition was demonstrated, with the strain showing heat sensitivity closer to that of a liquid (such as reconstituted infant formula) in a powder composed of crystalline particles.

The mechanics of increased thermotolerance of microorganisms in low $\mathrm{a}_{\mathrm{w}}$ environments is poorly understood. Fine et al. (2005) investigated the importance of particle size and $\mathrm{a}_{\mathrm{w}}$ in heat tolerance of yeast cells in a powder matrix. By modeling heat transfer through the particle, they could predict microbial destruction and account for the greater destruction of microorganisms on the periphery of glass beads compared with wheat 


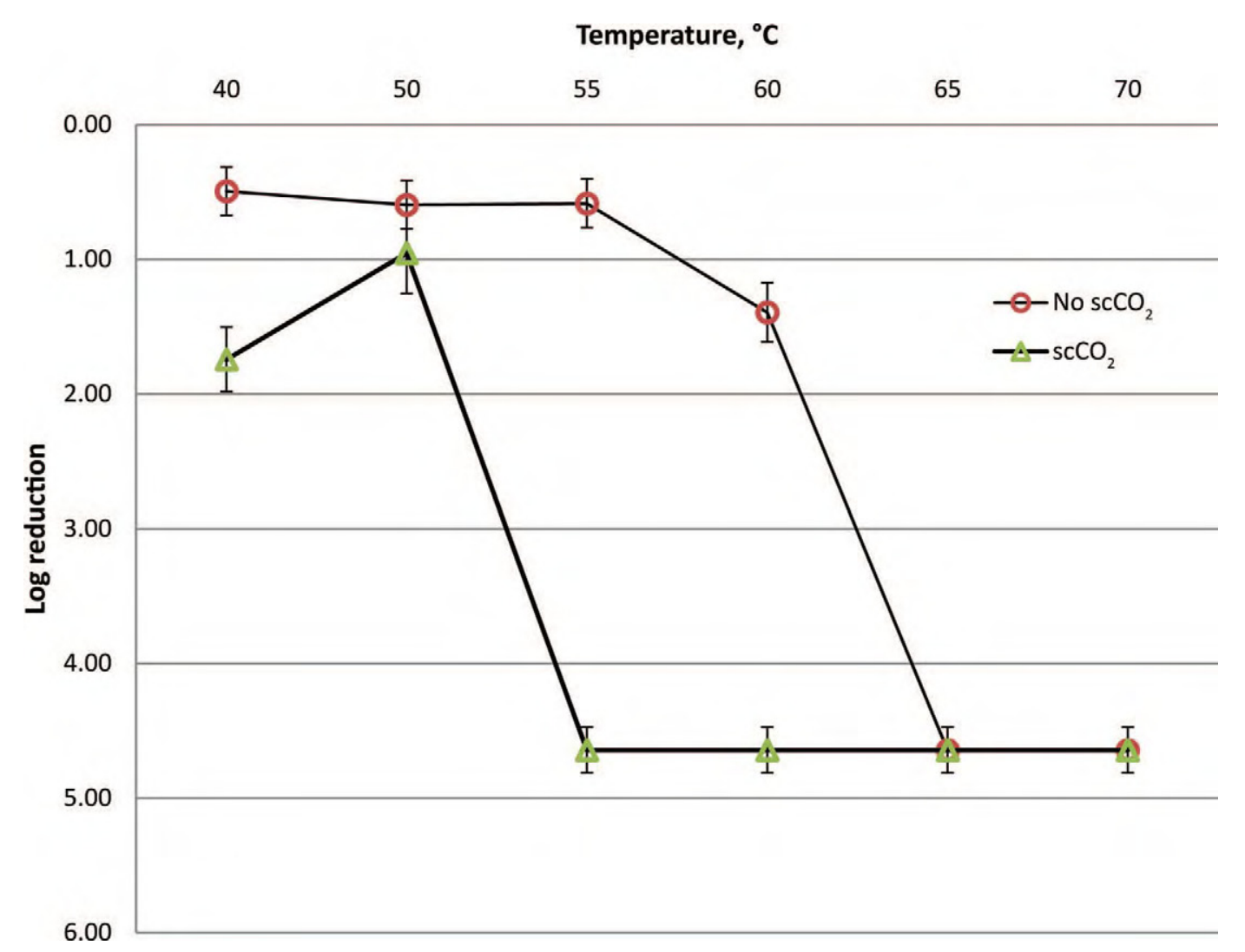

Figure 3. Effect of heat treatment (10 min) on anhydrated dextrose inoculated with Enterobacter pulveris 1160/04 (initial inoculum of 4.64 $\pm 0.17 \log _{10} \mathrm{cfu} / \mathrm{g}$ ) with $(\Delta)$ and without $(\bigcirc)$ supercritical $(\mathrm{sc}) \mathrm{CO}_{2}$ at $20 \mathrm{MPa}$. Color version available in the online PDF.

flour granules, where the cells were located outside and inside the particles. Given the experimental temperatures and short timeframe for system equilibration in the current study, we expect that both the water and Enterobacter cells introduced in the inoculation of the dextrose powder remained on the surface of the crystalline particles. The co-location of the small amount of water on the surface of the crystal particle would explain the increase in the measured $\mathrm{a}_{\mathrm{w}}$ of the powder, and its availability may have contributed to the decreased heat resistance of the bacterium. Therefore, a combination of more efficient heat transfer and water availability would explain the efficacy of the treatment processes for the dextrose powders. This hypothesis remains to be confirmed, and further studies are necessary to understand fully the behavior of microbes in complex powder matrices. It has been noted previously that relying on $\mathrm{a}_{\mathrm{w}}$ measurements has several limitations in predicting microbial food safety, and $\mathrm{a}_{\mathrm{w}}$ measurement should be used carefully, particularly regarding nonequilibrium situations (Chirife and Del Pilar Buera, 1996). The contrasting behavior of Enterobacter in 2 powder matrices of similar preinoculation $a_{w}$ values highlights the importance of considering particle com- position when examining microbial persistence in dry powdered food products.

The results presented here focus on the resistance of an Enterobacter strain to treatment in the immediate post-production situation. An important characteristic of these organisms is their ability to survive long periods (>2 yr) in the desiccated state (Chap et al., 2009). In our trials, a period of at least $2 \mathrm{~d}$ was allowed for stabilization of the inoculated bacteria. The majority of treatments and enumerations were performed within 1 wk of powder preparation. Therefore, we cannot comment on the long-term stability of Enterobacter in various powder matrices posttreatment.

\section{CONCLUSIONS}

Treatment with $\mathrm{scCO}_{2}$ for decontamination of PIF may be problematic because it did not efficiently reduce E. pulveris inoculated in commercial powders. This finding is in contrast to the results of Kim et al. (2010), who demonstrated the potential of the technology to effect a $6 \log _{10} \mathrm{cfu} / \mathrm{g}$ reduction of Cronobacter spp. in PIF. Clearly, more work is required to demonstrate the true value of $\mathrm{scCO}_{2}$ as a treatment for decontamination 
of PIF. In addition, the ability of these microorganisms to persist in the powder environment is influenced by particle composition but does not appear to require the full complement of PIF components. Further studies are required to understand fully the behavior of microbes in powder matrices before designing effective decontamination strategies.

\section{REFERENCES}

Beuchat, L. R., H. Kim, J. B. Gurtler, L. C. Lin, J. H. Ryu, and G. M. Richards. 2009. Cronobacter sakazakii in foods and factors affecting its survival, growth, and inactivation. Int. J. Food Microbiol. 136:204-213.

Breeuwer, P., A. Lardeau, M. Peterz, and H. M. Joosten. 2003. Desiccation and heat tolerance of Enterobacter sakazakii. J. Appl. Microbiol. 95:967-973.

Chap, J., P. Jackson, R. Siqueira, N. Gaspar, C. Quintas, J. Park, T. Osaili, R. Shaker, Z. Jaradat, S. H. P. Hartantyo, N. Abdullah Sani, S. Estuningsih, and S. J. Forsythe. 2009. International survey of Cronobacter sakazakii and other Cronobacter spp. in follow up formulas and infant foods. Int. J. Food Microbiol. 136:185-188.

Chirife, J., and M. Del Pilar Buera. 1996. Water activity, water glass dynamics, and the control of microbiological growth in foods. Crit. Rev. Food Sci. Nutr. 36:465-513.

Fine, F., E. Ferret, and P. Gervais. 2005. Thermal properties and granulometry of dried powders strongly influence the effectiveness of heat treatment for microbial destruction. J. Food Prot. 68:1041-1046.

Fine, F., and P. Gervais. 2005. A new high temperature short time process for microbial decontamination of seeds and food powders. Powder Technol. 157:108-113.

Gajdosova, J., K. Benedikovicova, N. Kamodyova, L. Tothova, E. Kaclikova, S. Stuchlik, J. Turna, and H. Drahovska. 2011. Analysis of the DNA region mediating increased thermotolerance at $58^{\circ} \mathrm{C}$ in Cronobacter sp. and other enterobacterial strains. Antonie van Leeuwenhoek 100:279-289.

Garcia-Gonzalez, L., A. H. Geeraerd, S. Spilimbergo, K. Elst, L. Van Ginneken, J. Debevere, J. F. Van Impe, and F. Devlieghere. 2007. High pressure carbon dioxide inactivation of microorganisms in foods: The past, the present and the future. Int. J. Food Microbiol. 117:1-28.

Healy, B., S. Cooney, S. O'Brien, C. Iversen, P. Whyte, J. Nally, J. J. Callanan, and S. Fanning. 2010. Cronobacter (Enterobacter saka- zakii): An opportunistic foodborne pathogen. Foodborne Pathog. Dis. $7: 339-350$

Jacobs, C., P. Braun, and P. Hammer. 2011. Reservoir and routes of transmission of Enterobacter sakazakii (Cronobacter spp.) in a milk powder-producing plant. J. Dairy Sci. 94:3801-3810.

Kandhai, M. C., A. E. Heuvelink, M. W. Reij, R. R. Beumer, R. Dijk, J. J. H. C. van Tilburg, M. van Schothorst, and L. G. M. Gorris. 2010. A study into the occurrence of Cronobacter spp. in The Netherlands between 2001 and 2005. Food Contr. 21:1127-1136.

Kim, S. A., O. Y. Kim, and M. S. Rhee. 2010. Direct application of supercritical carbon dioxide for the reduction of Cronobacter spp. (Enterobacter sakazakii) in end products of dehydrated powdered infant formula. J. Dairy Sci. 93:1854-1860.

Laroche, C., F. Fine, and P. Gervais. 2005. Water activity affects heat resistance of microorganisms in food powders. Int. J. Food Microbiol. 97:307-315.

Lehner, A., C. Fricker-Feer, K. Gschwend, and R. Stephan. 2010. Identification of Enterobacteriaceae and Cronobacter spp. in raw milk, milk concentrate and milk powder: Prevalence and genotyping. Arch. Lebensmittelhyg. 61:22-26.

Mullane, N., B. Healy, J. Meade, P. Whyte, P. G. Wall, and S. Fanning. 2008. Dissemination of Cronobacter spp. (Enterobacter sakazakii) in a powdered milk protein manufacturing facility. Appl. Environ. Microbiol. 74:5913-5917.

O'Brien, S., B. Healy, C. Negredo, W. Anderson, S. Fanning, and C. Iversen. 2009. Prevalence of Cronobacter species (Enterobacter sakazakii) in follow-on infant formulae and infant drinks. Lett. Appl. Microbiol. 48:536-541.

Podolak, R., E. Enache, W. Stone, D. G. Black, and P. H. Elliott. 2010. Sources and risk factors for contamination, survival, persistence, and heat resistance of Salmonella in low-moisture foods. J. Food Prot. 73:1919-1936.

Reich, F., R. Koenig, W. von Wiese, and G. Klein. 2010. Prevalence of Cronobacter spp. in a powdered infant formula processing environment. Int. J. Food Microbiol. 140:214-217.

Stephan, R., S. Van Trappen, I. Cleenwerck, C. Iversen, H. Joosten, P. De Vos, and A. Lehner. 2008. Enterobacter pulveris sp. nov., isolated from fruit powder, infant formula and an infant formula production environment. Int. J. Syst. Evol. Microbiol. 58:237-241.

Walsh, D., C. Molloy, C. Iversen, J. Carroll, C. Cagney, S. Fanning, and G. Duffy. 2011. Survival characteristics of environmental and clinically derived strains of Cronobacter sakazakii in infant milk formula (IMF) and ingredients. J. Appl. Microbiol. 110:697-703.

Wiebe, R., and V. L. Gaddy. 1941. Vapor phase composition of carbon dioxide-water mixtures at various temperatures and at pressures to 700 atmospheres. J. Am. Chem. Soc. 63:475-477. 